\title{
Evaluation of the Epidemiological Activities Surveillance Program for Communicable Diseases at the Primary Health Care Centers in Al-Najaf Governorate
}

\author{
Mohamed Abd Al-Hay Kamel Al- Ziyara ${ }^{1}$, Maliha Masoud Abdullah ${ }^{2}$, Khadija Shaaban Hassan ${ }^{2}$ \\ ${ }^{1}$ MSC Student, ${ }^{2}$ Assistant Professor, Middle Technical University College of Health \& Medical Technology, \\ Baghdad, Iraq
}

\begin{abstract}
Background: Surveillance of communicable diseases is an important tool for monitoring trends, identifying the target population for vaccination programs, and evaluating programs' effectiveness to prevent and control target diseases. Materials and Methods: A cross-sectional study, conducted at six health care sectors (Al Kufa sector, Northern sector, Southern sector, Al-Mishkhab sector, Al-Munadhira Sector, and Abbasiya sector), which include 24 out of 48 primary health care centers in Al Najaf governorate. were randomly chosen by multistage sampling technique from all sectors, then randomized samples from each sector. Results: Results shows that studied item subjected to evaluation was with a pass level on degree of " $\geq 50$ $\%$ regarding satisfied with the surveillance system. Conclusion: The current study demonstrates which all health centers had a pass level $>50$ except three main axes (Data Analysis, Epidemic Preparedness, and Training ) had weak evaluation level.
\end{abstract}

Keywords: epidemiological activities; surveillance program ;communicable diseases; primary health care centers; Al-Najaf Governorate

\section{Introduction}

Evaluation is an important part of infectious disease surveillance. The systematic and objective evaluation of monitoring determines the appropriateness, effectiveness and impact of these systems ${ }^{[1]}$.

Infectious disease surveillance is recognized to be the cornerstone of public health decision-making and practice. Surveillance data is essential for monitoring the health status of the population, detecting diseases and starting work to prevent further diseases, and contain public health problems. There is global recognition of the need to strengthen the disease surveillance and response system $^{[2]}$. Effective control of infectious diseases needs an effective disease surveillance system that provides information to act on priority communicable diseases. It is the basis for public health decision-making around the world. There is global recognition of the need to strengthen disease surveillance and response systems ${ }^{[2]}$.
Several developed countries have established a national infectious disease surveillance system and have stored the collected data in a central data repository. In these countries, the Ministry of Health is directly responsible for coordinating and supporting this system. Various organizations at the local and state level are working with the Ministry of Health to share data ${ }^{[4]}$.

\section{Aim of Study}

To evaluate the core activities and functions supporting the communicable disease surveillance system in terms of structure, performance, epidemic preparedness, and response at the level of all health facilities in Al Najaf governorate.

\section{Materials and Methods}

This is a descriptive, a cross-sectional study, conducted at six health care sectors (Al Kufa sector, Northern sector, Southern sector, Al-Mishkhab sector, Al-Munadhira Sector, and Abbasiya sector), which include 24 out of 48 primary health care centers in $\mathrm{Al}$ 
Najaf governorate. were randomly chosen by multistage sampling technique from all sectors, then randomized samples from each sector.

Data collection technique: The data collection was made by the use of WHO generic questionnaires for evaluation of the National communicable disease surveillance and response system ${ }^{[3]}$.

\section{Results}

1- national surveillance manual; Case Detection \& Registration

Table (1): Observed frequencies, percents, and summary statistics of health facilities with national surveillance manual and "Case Detection \& Registration" items for the studied PHCCs

\begin{tabular}{|c|c|c|c|c|c|c|c|}
\hline $\begin{array}{l}\text { Health facilities with national } \\
\text { surveillance manual }\end{array}$ & Resp. & No. & $\%$ & MS & SD & RS\% & Ev. \\
\hline \multirow{2}{*}{$\begin{array}{c}\text { Is there a national for surveillance at } \\
\text { this site? }\end{array}$} & Yes & 24 & 100 & \multirow{2}{*}{1.00} & \multirow{2}{*}{0.00} & \multirow{2}{*}{100} & \multirow{2}{*}{ All } \\
\hline & No & 0 & 0 & & & & \\
\hline \multirow{2}{*}{ Observe national surveillance manual ? } & Yes & 24 & 100 & \multirow{2}{*}{1.00} & \multirow{2}{*}{0.00} & \multirow{2}{*}{100} & \multirow{2}{*}{ All } \\
\hline & No & 0 & 0 & & & & \\
\hline Case Detection \& Registration & Resp. & No. & $\%$ & PMS & SD & PRS\% & Ev. \\
\hline \multirow{4}{*}{ The existence of a clinical register } & Yes & 24 & 100 & \multirow{4}{*}{1.00} & \multirow{4}{*}{0.00} & \multirow{4}{*}{100} & \multirow{4}{*}{ All } \\
\hline & No & 0 & 0 & & & & \\
\hline & Unknown & 0 & 0 & & & & \\
\hline & NA & 0 & 0 & & & & \\
\hline \multirow{4}{*}{$\begin{array}{c}\text { Observed the correct filling of the } \\
\text { clinical register during the previous } 30 \\
\text { days }\end{array}$} & Yes & 24 & 100 & \multirow{4}{*}{1.00} & \multirow{4}{*}{0.00} & \multirow{4}{*}{100} & \multirow{4}{*}{ All } \\
\hline & No & 0 & 0 & & & & \\
\hline & Unknown & 0 & 0 & & & & \\
\hline & NA & 0 & 0 & & & & \\
\hline \multirow{4}{*}{$\begin{array}{l}\text { Do you have a standard case definition } \\
\text { for: (each priority disease) ? }\end{array}$} & Yes & 19 & 79.2 & \multirow{4}{*}{0.79} & \multirow{4}{*}{0.41} & \multirow{4}{*}{79.0} & \multirow{4}{*}{$\geq 50 \%$} \\
\hline & No & 5 & 20.8 & & & & \\
\hline & Unknown & 0 & 0 & & & & \\
\hline & NA & 0 & 0 & & & & \\
\hline \multirow{4}{*}{$\begin{array}{l}\text { Observed the standard case definition } \\
\text { for: (each priority disease) }\end{array}$} & Yes & 14 & 58.3 & \multirow{4}{*}{0.58} & \multirow{4}{*}{0.50} & \multirow{4}{*}{58.0} & \multirow{4}{*}{$\geq 50 \%$} \\
\hline & No & 10 & 41.7 & & & & \\
\hline & Unknown & 0 & 0 & & & & \\
\hline & NA & 0 & 0 & & & & \\
\hline \multirow{4}{*}{$\begin{array}{l}\text { Observed the respondent correctly } \\
\text { diagnosing one of the country's priority } \\
\text { diseases using a standard case definition }\end{array}$} & Yes & 0 & 0 & \multirow{4}{*}{0.00} & & & \\
\hline & No & 24 & 100 & & & & \\
\hline & Unknown & 0 & 0 & & 0.00 & 0.00 & None \\
\hline & NA & 0 & 0 & & & & \\
\hline
\end{tabular}


Table (1) The results indicate that all the health centers have implemented the system of health facilities with national surveillance.so results showed that most of the items achieved good level of evaluation on degree of "All", and resting on pass level of evaluation on degree of " $\geq 50 \%$ ", except the last item of "Observed the respondent correctly diagnosing one of the country's priority diseases using a standard case definition" which was recorded poor evaluation on degree of "None".

\section{2-Data Reporting:}

Table (2): Observed frequencies, percents, and summary statistics of "Data Reporting" items for the studied PHCCs

\begin{tabular}{|c|c|c|c|c|c|c|c|}
\hline Data Reporting & Resp. & No. & $\%$ & MS & SD & RS\% & Ev. \\
\hline \multirow{4}{*}{$\begin{array}{l}\text { Have you lacked appropriate } \\
\text { surveillance forms at any time } \\
\text { during the last } 6 \text { months? }\end{array}$} & Yes & 8 & 33.3 & \multirow{4}{*}{0.33} & \multirow{4}{*}{0.48} & \multirow{4}{*}{33.0} & \multirow{4}{*}{$<50 \%$} \\
\hline & No & 16 & 66.7 & & & & \\
\hline & Unknown & 0 & 0 & & & & \\
\hline & NA & 0 & 0 & & & & \\
\hline \multirow{4}{*}{$\begin{array}{l}\text { The Presence of correct register of } \\
\text { targeted diseases as for Eradication }\end{array}$} & Yes & 0 & 0 & \multirow{4}{*}{0.00} & \multirow{4}{*}{0.00} & \multirow{4}{*}{0.00} & \multirow{4}{*}{ None } \\
\hline & No & 24 & 100 & & & & \\
\hline & Unknown & 0 & 0 & & & & \\
\hline & NA & 0 & 0 & & & & \\
\hline \multirow{4}{*}{$\begin{array}{l}\text { The Presence of correct register of } \\
\text { targeted diseases as for Elimination }\end{array}$} & Yes & 0 & 0 & \multirow{4}{*}{0.00} & \multirow{4}{*}{0.00} & \multirow{4}{*}{0.00} & \multirow{4}{*}{ None } \\
\hline & No & 24 & 100 & & & & \\
\hline & Unknown & 0 & 0 & & & & \\
\hline & NA & 0 & 0 & & & & \\
\hline \multirow{4}{*}{$\begin{array}{c}\text { The Presence of correct register of } \\
\text { targeted diseases as for Epidemic } \\
\text { prone }\end{array}$} & Yes & 0 & 0 & \multirow{4}{*}{0.00} & \multirow{4}{*}{0.00} & \multirow{4}{*}{0.00} & \multirow{4}{*}{ None } \\
\hline & No & 24 & 100 & & & & \\
\hline & Unknown & 0 & 0 & & & & \\
\hline & NA & 0 & 0 & & & & \\
\hline \multirow{4}{*}{$\begin{array}{c}\text { The Presence of correct register } \\
\text { of targeted diseases as for Major } \\
\text { public health importance }\end{array}$} & Yes & 0 & 0 & \multirow{4}{*}{0.00} & \multirow{4}{*}{0.00} & \multirow{4}{*}{0.00} & \multirow{4}{*}{ None } \\
\hline & No & 24 & 100 & & & & \\
\hline & Unknown & 0 & 0 & & & & \\
\hline & NA & 0 & 0 & & & & \\
\hline
\end{tabular}


Cont.. Table (2): Observed frequencies, percents, and summary statistics of "Data Reporting" items for the studied PHCCs

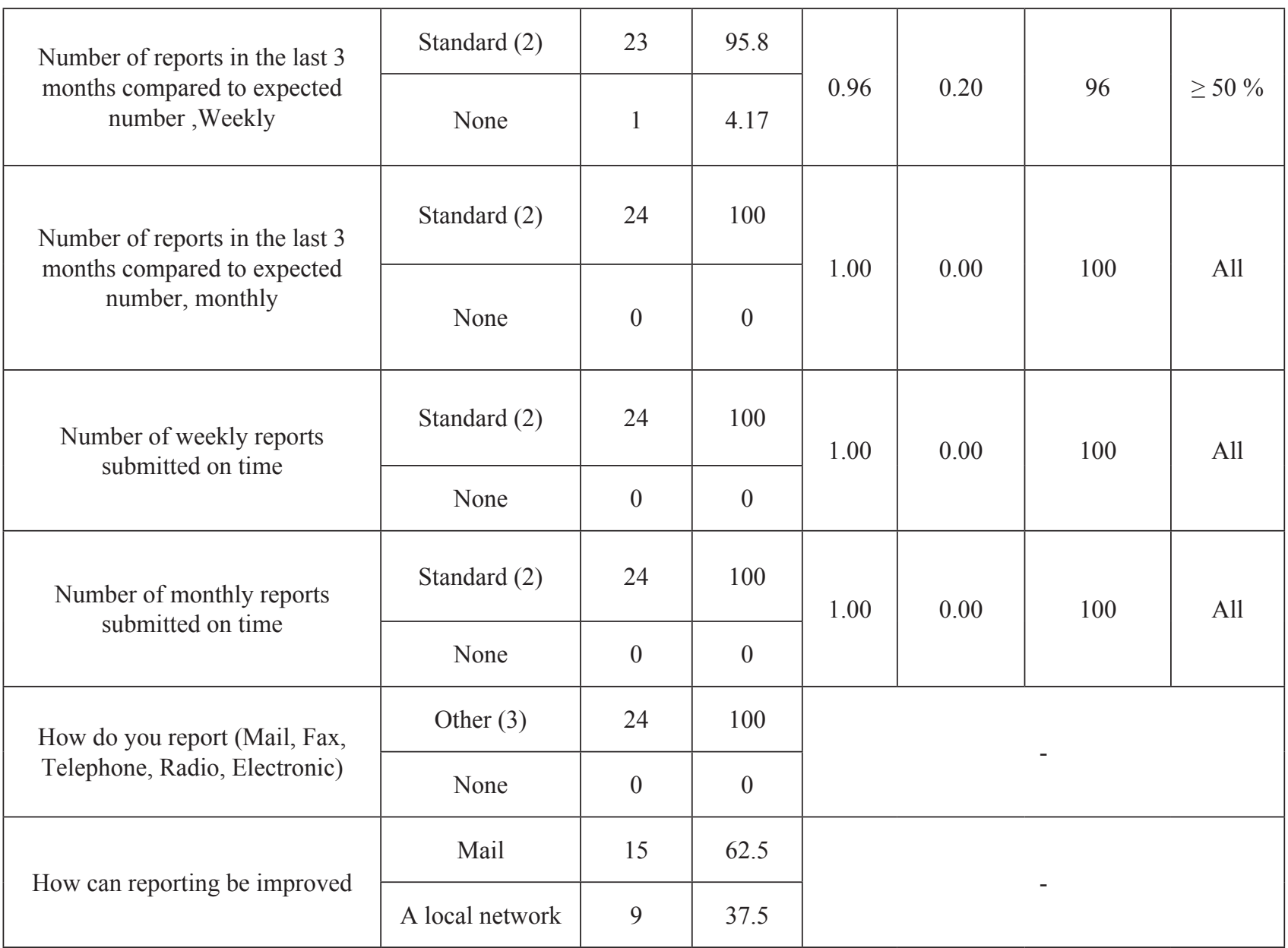

Table (2) demonstrate this study that that the existence of two items, namely "How do you report (Mail, Fax, Telephone, Radio, Electronic), How can reporting be improved" the content of which does not reflect the nature of the prevailing used in the current means of communication, which depends only on a receipt by hand (i.e. The Courier), and it is an option that does not contain the evaluation system, it was canceled from the evaluation process, and accordingly, the number of items subjected to evaluation became nine, three of which came with a high level of evaluation on the degree of "All", and one item subjected to pass evaluation on the degree of " $\geq 50 \%$ ", one item subjected to weak evaluation on the degree of " $<50 \%$ ", and the leftover items were subjected to poor evaluation on the degree of "None". 
3-Data Analysis:

Table (3): Observed frequencies, percents, and summary statistics of "Data Analysis " items for the studied PHCCs

\begin{tabular}{|c|c|c|c|c|c|c|c|}
\hline Data Analysis & Resp. & No. & $\%$ & MS & SD & RS\% & Ev. \\
\hline \multirow{4}{*}{ Observed description of data by age and sex } & Yes & 24 & 100 & \multirow{4}{*}{1.00} & \multirow{4}{*}{0.00} & \multirow{4}{*}{100} & \multirow{4}{*}{ All } \\
\hline & No & 0 & 0 & & & & \\
\hline & Unknown & 0 & 0 & & & & \\
\hline & NA & 0 & 0 & & & & \\
\hline \multirow{4}{*}{$\begin{array}{l}\text { Observed description of data by place (locality, } \\
\text { village, work site etc) }\end{array}$} & Yes & 21 & 87.5 & \multirow{4}{*}{0.87} & \multirow{4}{*}{0.34} & \multirow{4}{*}{87.0} & \multirow{4}{*}{$\geq 50 \%$} \\
\hline & No & 3 & 12.5 & & & & \\
\hline & Unknown & 0 & 0 & & & & \\
\hline & NA & 0 & 0 & & & & \\
\hline \multirow{4}{*}{ Observed description of data by time } & Yes & 0 & 0 & \multirow{4}{*}{0.00} & \multirow{4}{*}{0.00} & \multirow{4}{*}{0.00} & \multirow{4}{*}{ None } \\
\hline & No & 24 & 100 & & & & \\
\hline & Unknown & 0 & 0 & & & & \\
\hline & NA & 0 & 0 & & & & \\
\hline \multirow{4}{*}{ Observed line graph of cases by time } & Yes & 0 & 0 & \multirow{4}{*}{0.00} & \multirow{4}{*}{0.00} & \multirow{4}{*}{0.00} & \multirow{4}{*}{ None } \\
\hline & No & 24 & 100 & & & & \\
\hline & Unknown & 0 & 0 & & & & \\
\hline & NA & 0 & 0 & & & & \\
\hline \multirow{4}{*}{$\begin{array}{l}\text { Do you have an action threshold for any of the } \\
\text { country priority diseases }\end{array}$} & Yes & 0 & 0 & \multirow{4}{*}{0.00} & \multirow{4}{*}{0.00} & \multirow{4}{*}{0.00} & \multirow{4}{*}{ None } \\
\hline & No & 24 & 100 & & & & \\
\hline & Unknown & 0 & 0 & & & & \\
\hline & NA & 0 & 0 & & & & \\
\hline \multirow{4}{*}{ Observed presence of demographic data at site } & Yes & 24 & 100 & \multirow{4}{*}{1.00} & \multirow{4}{*}{0.00} & \multirow{4}{*}{100} & \multirow{4}{*}{ All } \\
\hline & No & 0 & 0 & & & & \\
\hline & Unknown & 0 & 0 & & & & \\
\hline & NA & 0 & 0 & & & & \\
\hline \multirow{4}{*}{ Observed rates derived from demographic data } & Yes & 0 & 0 & & & & \\
\hline & No & 24 & 100 & & & & \\
\hline & Unknown & 0 & 0 & 0.00 & 0.00 & 0.00 & None \\
\hline & NA & 0 & 0 & & & & \\
\hline
\end{tabular}


Table (3) Results shows that the number of items subjected to evaluation with good level on degree of "All" were only two, which namely " Observed description of data by age and sex, and Observed presence of demographic data at site", and one item subjected to pass evaluation on degree of " $\geq 50 \%$ ", which namely
"Observed description of data by place (locality, village, work site etc)", and the leftover items were subjected to poor evaluation on degree of "None", which namely " Observed description of data by time, Observed line graph of cases by time, Do you have an action threshold for any of the country priority diseases, and Observed rates derived from demographic data".

\section{4-Epidemic Preparedness and Supervision:}

Table (4): Observed frequencies, percents, and summary statistics of "Epidemic Preparedness and Epidemic Response "and "Supervision and Training and Satisfaction with Surveillance " items for the studied PHCCs

\begin{tabular}{|c|c|c|c|c|c|c|c|}
\hline Epidemic Preparedness & Resp. & No. & $\%$ & MS & SD & RS\% & Ev. \\
\hline \multirow{4}{*}{$\begin{array}{l}\text { Observed the existence of a written } \\
\text { case management }\end{array}$} & Yes & 3 & 12.5 & \multirow{4}{*}{0.13} & \multirow{4}{*}{0.34} & \multirow{4}{*}{13.0} & \multirow{4}{*}{$<\mathbf{5 0 \%}$} \\
\hline & No & 21 & 87.5 & & & & \\
\hline & Unknown & $\mathbf{0}$ & $\mathbf{0}$ & & & & \\
\hline & NA & $\mathbf{0}$ & $\mathbf{0}$ & & & & \\
\hline Epidemic Response & Resp. & No. & $\%$ & MS & SD & RS\% & Ev. \\
\hline \multirow{4}{*}{$\begin{array}{c}\text { Has the health facility } \\
\text { implemented prevention and } \\
\text { control measures based on local } \\
\text { data for at least one epidemic } \\
\text { prone disease? }\end{array}$} & Yes & 24 & 100 & \multirow{4}{*}{1.00} & \multirow{4}{*}{0.00} & \multirow{4}{*}{100} & \multirow{4}{*}{ All } \\
\hline & No & $\mathbf{0}$ & $\mathbf{0}$ & & & & \\
\hline & Unknown & $\mathbf{0}$ & $\mathbf{0}$ & & & & \\
\hline & NA & $\mathbf{0}$ & $\mathbf{0}$ & & & & \\
\hline \multirow{20}{*}{$\begin{array}{l}\text { Observed supervision report or } \\
\text { any evidence for appropriate } \\
\text { review of surveillance practices }\end{array}$} & Yes & 10 & 41.7 & \multirow{20}{*}{0.42} & \multirow{20}{*}{0.31} & \multirow{20}{*}{42.00} & \multirow{20}{*}{$<\mathbf{5 0 \%}$} \\
\hline & No & 14 & 58.3 & & & & \\
\hline & Unknown & $\mathbf{0}$ & $\mathbf{0}$ & & & & \\
\hline & NA & $\mathbf{0}$ & $\mathbf{0}$ & & & & \\
\hline & Resp. & No. & $\%$ & & & & \\
\hline & 1 - 8 & 8 & 33.33 & & & & \\
\hline & $9-16$ & 12 & 50.00 & & & & \\
\hline & 17 _ 24 & 4 & 16.67 & & & & \\
\hline & Yes & 15 & 62.5 & & & & \\
\hline & No & 9 & 37.5 & & & & \\
\hline & Resp. & No. & $\%$ & & & & \\
\hline & Yes & 6 & 25 & & & & \\
\hline & No & 18 & 75 & & & & \\
\hline & Unknown & $\mathbf{0}$ & $\mathbf{0}$ & & & & \\
\hline & NA & $\mathbf{0}$ & 0 & & & & \\
\hline & Resp. & No. & $\%$ & & & & \\
\hline & Yes & 15 & 62.5 & & & & \\
\hline & No & 6 & 25 & & & & \\
\hline & Unknown & 3 & 12.5 & & & & \\
\hline & NA & 0 & 0 & & & & \\
\hline
\end{tabular}


Table (4) Results shows that studied item subjected to evaluation was with a weak level on degree of " $<$ $50 \%$ ", which namely "Observed the existence of a written case management".so studied item subjected to evaluation with good level on degree of "All", which has namely "Has the health facility implemented prevention and control measures based on local data for at least one epidemic prone disease ?", and leftover item was subjected to evaluation of weak level on degree of " $<50 \%$ ", which namely "Observed supervision report or any evidence for appropriate review of surveillance practices".

So in table (4) Results shows that studied item subjected to evaluation with weak level on degree of "< $50 \%$ ", which has namely "How many times have you been supervised in the last 6 months?", on applying the standard limit for one visit per week, which was classified into three periods, which are eight supervisions per two months.So studied item subjected to evaluation was with a weak level on degree of " $<50 \%$ ", which namely "Have you been trained in disease surveillance and epidemic management?" As well as results shows that studied item subjected to evaluation was with a pass level on degree of " $\geq 50 \%$ ", which namely "Are you satisfied with the surveillance system ?".

\section{Discussion}

Regarding case detection and registration, the study found that most studied PHCCs had a clinical register with concentrate the correct filling of the clinical register during the previous 30 days, except the last item namely "Observed the respondent correctly diagnosing one of the country's priority diseases using a standard case definition" which was recorded poor evaluation on degree of none .This result is disagreement with published study findings conducted in Baghdad ${ }^{[5]}$, which found that ranged $(86 \%$, and $98 \%)$ of the study centers had a clinical register, and concentrate the correct filling of the clinical register during the previous 30 days.

The results of this study indicated that all PHCCs $(100 \%)$ had no correct register of targeted diseases as for (Eradication, Elimination, Epidemic prone, and Major public health importance). This result is in agreement with the finding another similar study conducted in
Baghdad ${ }^{[5]}$, which found that all the study centers had no correct register of targeted diseases as for (Eradication, Elimination, Epidemic prone, and Major public health importance). In addition to that, the number of reports in the last 3 months compared to the expected number, (i.e. the standard) weekly, was (96.0\%) for studied PHCCs. To the best of our knowledge, there is no similar previous study, but in comparison with a study conducted in Babylon governorate (Kareem and Alalawe, 2020), which found that all PHCCs (100\%) concerning a weekly report form is available and implemented.

The results of this study indicated that all PHCCs $(100 \%)$ were the description of data by (age, and sex), and at the same time, there is demographic data at the site. These results agreed with the findings similar study was done in Baghdad ${ }^{[8]}$, which found that all the health facilities $(100 \%)$ were the description of data by (age, and sex), and had demographic data at the site.

In this study, all PHCCs (100\%) had no action threshold for any of the country's priority diseases. This result is in agreement with the finding another study conducted in Mosul ${ }^{[6]}$. which found that only (12.1\%) of the health centers had an action threshold for any of the country's priority diseases.

The results of this study indicated that only (13.0\%) of the studied PHCCs having an observed the existence of a written case management, which scoring poor evaluation by the proposed scales. This result is in agreement with a previous study done in Sudan ${ }^{[9] \cdot}$ which found that all the health centers $(100 \%)$ had no written case management protocol for 1 epidemic-prone disease.

As for the epidemic response, this study showed that all PHCCs $(100 \%)$ had implemented prevention and control measures based on local data for at least one epidemic-prone disease. This result disagrees with the finding study conducted in Sudan [9]., which found that all the study centers $(100 \%)$ had no implemented prevention and control measures based on local data for at least one epidemic-prone disease.

The results of this study indicated that $(42.0 \%)$ of studied PHCCs have supervision report or any evidence for appropriate review of surveillance practices. This result disagrees with the finding study done in Wasit ${ }^{[10]}$, 
which found that $(96.1 \%)$ of the health centers had on supervision report or any evidence for appropriate review of surveillance practices.

In this study, the percent of relative sufficiency of the number of meetings has these health facilities conducted with community members in the past six months was (45.2\%), which scored with poor evaluated. This result differs from another similar study conducted in Baghdad ${ }^{[8]}$, which found that the mean score of the number of meetings has these health facilities conducted with the community members in the past six months was (4.08\%). Finally, this study has revealed that all studied PHCCs $(100 \%)$ concerning observed the minutes or report of at least 1 meeting between the health facility team and the community members within the six months. This result is in agrees completely with the finding study done in Nigeria ${ }^{[11] .}$

The results of this study indicated that (43.17\%) of studied PHCCs having a times that had been supervised in the last 6 months, which has scored poor. This result disagrees with the finding study done in Wasit ${ }^{[10]}$, which found that $(66.5 \%)$ of the health centers had on supervision report or any evidence for appropriate review of surveillance practices.

The current study demonstrates that only (25.0\%) of studied PHCCs have members trained in disease surveillance and epidemic management, which has scored poor level by a proposed evaluation. This result disagreed with the finding study conducted in Tanzania ${ }^{[\mathbf{1 2}]}$. which found that all the health centers $(100 \%)$ have no members trained in disease surveillance and epidemic management. A possible explanation for this result is the failure to periodically hold training courses or seminars by the public health department in the governorate for workers in communicable disease units about the epidemiological surveillance system.

The current study demonstrates satisfaction with the surveillance system in studied health centers revealed that $(75.0 \%)$ were satisfied with the surveillance system, which had scored pass degree (i.e. $\geq 50 \%$ ). This result differs from another similar study conducted in Baghdad $^{[8]}$. which found that only (20\%) of the study samples were satisfied with the surveillance system.
Regarding opportunities are there for the integration of surveillance activities and functions, the study showed that $(16.7 \%$ and $8.3 \%)$ of studied PHCCs were required for training and personnel, respectively. These results asymptotical from a previous study done in Wasit ${ }^{[10]}$. , which found that only $(9.8 \%)$ of the health centers had training opportunities, and $(25.5 \%)$ of PHCCs had adequate personnel.

\section{Conclusions}

1. The current study demonstrates which all health centers had a pass level $>50$ except three main axes (Data Analysis, Epidemic Preparedness, and Training ) had weak evaluation level.

2. The national surveillance manual for communicable diseases was present in all surveillance units at health facilities.

\section{Conflict of Interest: None}

\section{Source of Findings: None}

Ethical Clearance: None

\section{References}

[1] Miller,M. P, Roche, Spencer, J. and Deeble, M. "Evaluation of Australia's National Notifiable Disease Surveillance System.," Commun. Dis. Intell.2004, vol. 28, no. 3, pp. 311-323.

[2] World Health Organization, "Communicable disease surveillance and response systems: guide to monitoring and evaluating," Lyon [France]: World Health Organization, 2006.

[3] World Health Organization, "Protocol for the assessment of national communicable disease surveillance and response systems: guidelines for assessment teams," World Health Organization, 2001.

[4] Janati, A.M. Hosseiny, M. M. Gouya, Moradi, G. and Ghaderi, E. "Communicable disease reporting systems in the world: A systematic review article," Iran. J. Public Health,2015 vol. 44, no. 11, pp. 1453-1465.

[5] Kadhum, S.A "Assessment of Communicable Diseases Surveillance System Activities in Phc Centers in Baghdad," Res. Artic. Kadhum. World 
J. Pharm. 2019.Res. www.wjpr.net, vol. 8, no. 7, p. 137, doi: 10.20959/wjpr20197-15056.

[6] AL-NEAMI, M.A and AL-JAWADI,A.A "Assessment of infectious diseases surveillance system in Mosul, Iraq," Duhok Med. J., 2008.. 2, no. 1 , pp. 127-140.

[7] Kareem, Q.A and Alalawe, S.M"Evaluating the Quality of Primary Health Care Services in Babylon Governorate, Iraq," Health (Irvine. Calif)., 2020.vol. 18, no. 78.3, pp. 5-21.

[8] Khaleefah, J.A "ASSESSMENT OF COMMUNICABLE DISEASES SURVEILLANCE SYSTEM ACTIVITIES IN PRIMARY HEALTH CARE CENTERS IN BAGHDAD GOVERNORATE,” 2013.

[9] Sahal, N. Reintjes, N, Eltayeb, E.M, and Aro, A.R,"AAssessment of core activities and supportive functions for the communicable diseases surveillance system in Khartoum state, Sudan, 2005-2007," EMHJ-Eastern Mediterr.
Heal. Journal, 2010.16 (12), 1204-1210.

[10] Abbas, T.M, Saeed, A. R. K. H and Tawfeeq, W. F. “Assessment of Health Facilities' Performance of Surveillance Activities for Childhood VaccinePreventable Diseases at Health Facilities in Wasit Governorate/Iraq/2010,” Med. J. Babylon, 2012. vol. 9, no. 4, pp. 901-911,

[11] Abubakar, A. A, Sambo, M. N. Idris, K. Sabitu, and Nguku, P. "Assessment of integrated disease surveillance S. H.and response strategy implementation in selected Local Government Areas of Kaduna state," Ann. Niger. Med.,2013, vol. 7, no. 1, p. 14.

[12] Nsubuga, P. Eseko, N, Tadesse, W, Ndayimirije, N, Stella, C. and McNabb, S. "Structure and performance of infectious disease surveillance and response, United Republic of Tanzania, 1998," Bull. World Health Organ., 2002,vol. 80, pp. 196-203. 